\title{
Viscosity Solution in Multi Time Hybrid Games
}

\author{
Constantin $U^{*}$, Elena LD and Ionel Ț \\ Department of Mathematics and Informatics, University Politehnica of Bucharest, Romania
}

Submission: February 12, 2018; Published: February 22, 2018

*Corresponding author: Constantin Udriște, Professor, Department of Mathematics and Informatics, Faculty of Applied Sciences, University Politehnica of Bucharest, Splaiul Independentei 313, R0-060042, Bucharest, Romania; Email: udriste@mathem.pub.ro

\section{Opinion}

In a multi time hybrid differential game with mechanical work payoff, the multi time upper value function and the multi time lower value function are viscosity solutions of new PDEs of type Hamilton-Jacobi-Isaacs. A similar statement is true for the case of multiple integral payoff. All variables and functions must satisfy suitable conditions [1-3]. One of important evolution problem is a multi time hybrid differential game, with two teams of players, whose Bolza payoff is the sum between a path independent curvilinear integral (mechanical work) and a function of the final event (the terminal cost, penalty term) and whose evolution PDE is an m-flow.

Generally, we use a larger family of similar multi time problems containing the functional

$$
J_{x, t}(u(\cdot), v(\cdot))=\int_{\Gamma_{t T}} L_{\alpha}\left(s, x(s), u_{\alpha}(s), v_{\alpha}(s)\right) d s^{\alpha}+g(x(T)),
$$

and the evolution constraint (Cauchy problem for first order PDEs system)

$$
\frac{\partial x^{i}}{\partial s^{\alpha}}(s)=X_{\alpha}^{i}\left(s, x(s), u_{\alpha}(s), v_{\alpha}(s)\right), x(t)=x, s \in \Omega_{t T} \subset \mathbb{R}_{+}^{m}, x \in \mathbb{R}^{n} .
$$

Let $\Psi$ and $\Phi$ be suitable strategies of the two teams of players:

(i) The function is called the multi time lower value function;

$$
m(t, x)=\min _{\Psi \in \mathcal{V}} \max _{u(\cdot) \in U} J_{t, x}(u(\cdot), \Psi[u](\cdot))
$$

The function is called the multi time upper value function.

$$
M(t, x)=\max _{\Phi \in \mathcal{U}} \min _{v(\cdot) \in V} J_{t, x}(\Phi[v](\cdot), v(\cdot))
$$

The original key idea is that the multi time upper value function or the multi time lower value function are solutions of some PDEs, defined below. Our PDEs contain some implicit assumptions and are valid under certain conditions which are defined and analyzed for multi time hybrid differential games:

(i) The multi time upper value function $M(t, x)$ is the viscosity solutions of the multitime upper PDE

$$
\frac{\partial M}{\partial t^{\alpha}}(t, x)+\min _{v_{\alpha} \in \mathcal{V}} \max _{u_{\alpha} \in \mathcal{U}}\left\{\frac{\partial M}{\partial x^{i}}(t, x) X_{\alpha}^{i}\left(t, x, u_{\alpha}, v_{\alpha}\right)+L_{\alpha}\left(t, x, u_{\alpha}, v_{\alpha}\right)\right\}=0,
$$

which satisfies the terminal condition $M(T, x)=g(x)$.

The multi time lower value function $m(t, x)$ is the viscosity solution of the multi time lower PDE

$$
\frac{\partial m}{\partial t^{\alpha}}(t, x)+\max _{u_{\alpha} \in \mathcal{U}} \min _{v_{\alpha} \in \mathcal{V}}\left\{\frac{\partial m}{\partial x^{i}}(t, x) X_{\alpha}^{i}\left(t, x, u_{\alpha}, v_{\alpha}\right)+L_{\alpha}\left(t, x, u_{\alpha}, v_{\alpha}\right)\right\}=0,
$$

which satisfies the terminal condition $m(T, x)=g(x)$. These statements are based on the following contradict Lemma:

Let

$$
\omega \in C^{1}\left(\Omega_{0 T} \times \mathbb{R}^{n}\right) .
$$

(a) If $M-\omega$ attains a local maximum at $\left(t_{0}, x_{0}\right) \in \Omega_{0 T} \times \mathbb{R}^{n}$ $\times\left(\mathrm{t}_{0^{\prime}}, \mathrm{x}_{0}\right) \in \Omega 0 \mathrm{~T} \times \mathrm{R}_{\mathrm{n}}$ and $\omega_{t^{\alpha}}\left(t_{0}, x_{0}\right)+H_{\alpha}^{+}\left(t_{0}, x_{0}, \frac{\partial \omega}{\partial x^{i}}\left(t_{0}, x_{0}\right)\right) \leq-\theta_{\alpha}<0$,

Then, for all vectors $h=\left(h^{\alpha}\right)$, with sufficiently small $\|h\|$, there exists a control $v=\left(v_{\alpha}\right) \in \mathcal{V}\left(t_{0}\right)$ such that the relation (2) holds for all strategies $\Phi \in \mathcal{A}\left(t_{0}\right)$.

(b) If $M-\omega$ attains a local minimum at $\left(t_{0}, x_{0}\right) \in \Omega_{0 T} \times \mathbb{R}^{n}$ and $\omega_{t^{\alpha}}\left(t_{0}, x_{0}\right)+H_{\alpha}^{+}\left(t_{0}, x_{0}, \frac{\partial \omega}{\partial x^{i}}\left(t_{0}, x_{0}\right)\right) \geq \theta_{\alpha}>0$,

Then, for all vectors $h=\left(h^{\alpha}\right)$, with sufficiently small $\|h\|$, there exists a control $u=\left(u_{\alpha}\right) \in \mathcal{U}\left(t_{0}\right)$ such that the relation (5) holds for all strategies $\Psi \in \mathcal{B}\left(t_{0}\right)$.

Single time game theory has yielded deep insights into biological phenomena for almost a century. One topic was to give the central model of replicator dynamics in evolutionary processes. Over the last few years, multi time game theory has contributed substantial ideas to all fields. The work presented here is inspired by our concepts regarding multi time optimal control problems. One way of understanding new insights in deformation phenomena and complexity in nature is the multi temporal evolution described in the papers [1-3]. 


\section{References}

1. Udriște C (2011) Multi time maximum principle for curvilinear integral cost. Balkan J Geom Appl 16(1): 128-149.

2. Udrişte C, Tevy I (2011) Multi time dynamic programming for multiple integral actions. J Glob Optim 51(2): 345-360.

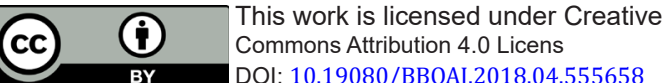

DOI: 10.19080/BBOAJ.2018.04.555658
3. Udriste C, Tevy I, Otobîcu EL (2017) Viscosity solutions of divergence type PDEs associated to multi time hybrid games. UPB Sci Bull Series A 79(2): 3-10.

\section{Your next submission with Juniper Publishers} will reach you the below assets

- Quality Editorial service

- Swift Peer Review

- Reprints availability

- E-prints Service

- Manuscript Podcast for convenient understanding

- Global attainment for your research

- Manuscript accessibility in different formats

( Pdf, E-pub, Full Text, Audio)

- Unceasing customer service

Track the below URL for one-step submission https://juniperpublishers.com/online-submission.php 